\title{
Multiple neuro-endocrine tumours complicating chronic atrophic gastritis: the cloak that hides the dagger
}

\author{
Richard Bamford ${ }^{1}$, Neil A Shepherd ${ }^{2}$ \\ 1. Department of Upper GI Surgery, Gloucestershire Royal Hospital, Great Western Road, Gloucester, UK. \\ 2. Gloucestershire Cellular Pathology Laboratory, Cheltenham General Hospital, Sandford Road, Cheltenham, UK.
}

Correspondence: Richard Bamford. Address: General Surgery Specialist Trainee. Department of Upper GI Surgery. Gloucestershire Royal Hospital, Great Western Road, Gloucester, UK. E-mail: richardbamford@doctors.org.uk

Received: October 8, 2014

DOI : $10.5430 /$ crcp.v2n4p19
Accepted: April 12, 2015

URL: http://dx.doi.org/10.5430/crcp.v2n4p19

\section{Abstract}

Neuro-endocrine tumours of the stomach are most likely to be seen as a complication of chronic atrophic gastritis and are usually multiple, small and indolent. Much more rarely, similar tumours can occur in Zollinger-Ellison syndrome and those tumours are also usually relatively benign. Thus most neuro-endocrine tumours of the stomach, especially when multiple, are treated relatively conservatively. Here we present two cases where the initial biopsies suggested that scenario but further investigations indicated more aggressive tumours, which ultimately represented mixed adeno-neuroendocrine carcinomas (MANECs) and frank adenocarcinomas, demanding a much more radical management strategy. Whislt therapeutic conservatism is appropriate for small and multiple neuro-endocrine tumours complicating chronic atrophic gastritis, the potential for other complications of chronic atrophic gastritis in the stomach, namely MANECs and adenocarcinoma, should always be borne in mind and evidence for those tumours sought by the multi-disciplinary team.

\section{Key words}

Neuroendocrine tumour, Carcinoid, Stomach, mixed adeno-neuroendocrine carcinomas, Chronic atrophic gastritis, Zollinger-Ellison syndrome, Adenocarcinoma

\section{I ntroduction}

Neuro-endocrine tumours (formerly known as carcinoids) of the gastrointestinal tract have distinct clinical and pathological characteristics dependent on their location ${ }^{[1,2]}$. In the stomach, there are four main types of neuro-endocrine tumour, determined largely by the presence of absence of specific associated diseases ${ }^{[3]}$. In most Western countries, at least, the commonest type arises on a basis of chronic atrophic gastritis (CAG): these are usually small, often multiple and have an indolent behavior ${ }^{[3]}$. In general, conservative management is advocated, unless the tumour shows adverse cytological features or is larger than $20 \mathrm{~mm}{ }^{[4]}$. Typically endoscopic mucosal resection (EMR) of larger lesions is the appropriate management ${ }^{[5,6]}$. In CAG, a raised serum gastrin is the pathogenetic mechanism that drives proliferation of enterochromaffin-like cells (ECLC) and the formation of tumours thereof ${ }^{[7,8]}$. Similarly, multiple endocrine neoplasia type 1 (MEN 1), associated with the Zollinger-Ellison syndrome, with a gastrinoma usually in the duodenum, results in raised levels of gastrin and the promotion of gastric ECLC tumours. In that disease, a somewhat more aggressive phenotype of gastric neuro-endocrine tumours may result but most ECLC tumours in the syndrome are also indolent ${ }^{[3,7]}$. 
In distinct contrast, sporadic neuro-endocrine tumours are often single and relatively large ${ }^{[3,8]}$. They are more likely to demonstrate aggressive characteristics, both clinically and histopathologically, and they may require a more aggressive management strategy ${ }^{[3,8-10]}$. Additionally, there is a very rare type of neuro-endocrine tumour associated with inherent abnormalities of parietal cells ${ }^{[11]}$. Because of their rarity, the management of such tumours is not well defined.

Finally, and causing major diagnostic challenges on biopsy material, there are mixed tumours featuring both neuroendocrine and epithelial differentiation. These tumours, known as mixed adeno-neuroendocrine carcinomas (MANECs), tend to behave according to their epithelial component and are likely to be more aggressive neoplasms than pure neuroendocrine tumours arising on a basis of CAG. Nevertheless biopsies may miss one or other of the components and thus may not be reflective of the behaviour of such tumours ${ }^{[12,13]}$. It should also be remembered that CAG itself also predisposes to pure epithelial tumours, namely adenomas and adenocarcinomas, in the stomach and the natural history and treatment of the latter will be very different to that of small neuro-endocrine tumours of the stomach ${ }^{[14-16]}$.

\section{Case presentation}

\subsection{Case 1}

A 70-year-old man presented with epigastric pain and dyspepsia. He underwent oesophagogastroduodenoscopy (OGD), which revealed multiple polypoid lesions in the gastric body. Biopsies revealed low-grade neuro-endocrine tumours complicating chronic atrophic gastritis. The patient was treated with proton pump inhibitors and was planned for close endoscopic surveillance. However, the patient re-presented with persistent symptoms three months later and underwent a further OGD and Computed Tomography (CT) scan of his abdomen. The CT scan revealed lymphadenopathy over the lesser curve of the stomach and an infiltrating tumour adjacent to the oesophago-gastric junction (OGJ) in the upper stomach. Repeat OGD again revealed gastric polyps and biopsies showed chronic atrophic gastritis and multiple lowgrade neuro-endocrine tumours.

Although the pathological diagnosis was one of multiple, apparently low-grade, neuro-endocrine tumours, in MultiDisciplinary Team Meeting (MDTM) discussion it was agreed that the OGJ tumour and the lymphadenopathy demanded aggressive treatment and the patient proceeded to total gastrectomy. This specimen revealed a nodular tumour mass $54 \mathrm{~mm}$ in diameter, just below the oesophago-gastric junction. There were also multiple small nodules and two larger nodules, $34 \mathrm{~mm}$ maximum dimension, macroscopically in keeping with multiple neuro-endocrine tumours arising on a basis of chronic atrophic gastritis (see Figure 1).

Microscopically the findings were of chronic atrophic gastritis with evidence of enterochromaffin-like cell hyperplasia, "dysplasia", "micro-carcinoid" formation and frank neuro-endocrine tumours (see Figure 2). The two larger nodules showed the features of MANEC tumours (see Figure 3) whilst the largest tumour, that just below the OGJ, was a primary gastric adenocarcinoma (pT4, pN2, pMX) with extensive subserosal and serosal spread and lymphatic and vascular invasion.

Figure 1. The gastrectomy of Case 1. The oesophageal margin is central and above. Adjacent to it, in the upper stomach, is the impression of a large mass, the adenocarcinoma, whilst the body of the stomach shows multiple polypoid nodules, most of them low grade neuroendocrine tumours. Further, at right, there is a larger umbilicated lesion, which was shown histologically to be a MANEC.

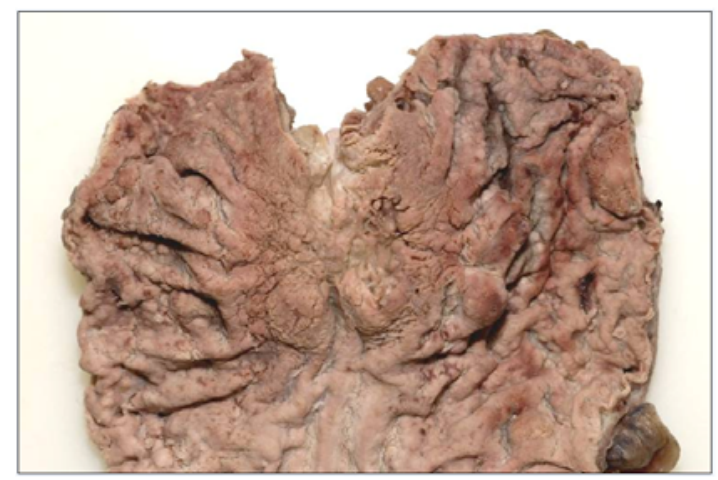

ISSN 2331-2726 E-ISSN 2331-2734 
Figure 2. Case 1. The gastric mucosa shows neuro-endocrine hyperplasia and the formation of small "micro-carcinoids", well seen here at the deep aspect of the mucosa.

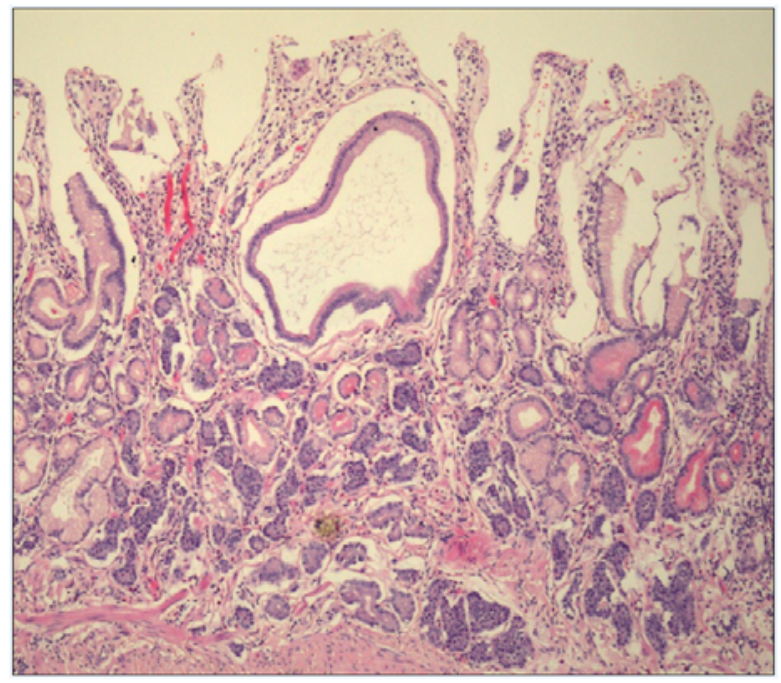

Figure 3. Case 1. This shows one of the MANEC tumours. Much of this field shows neuroendocrine tumour but there is obvious glandular differentiation superiorly.

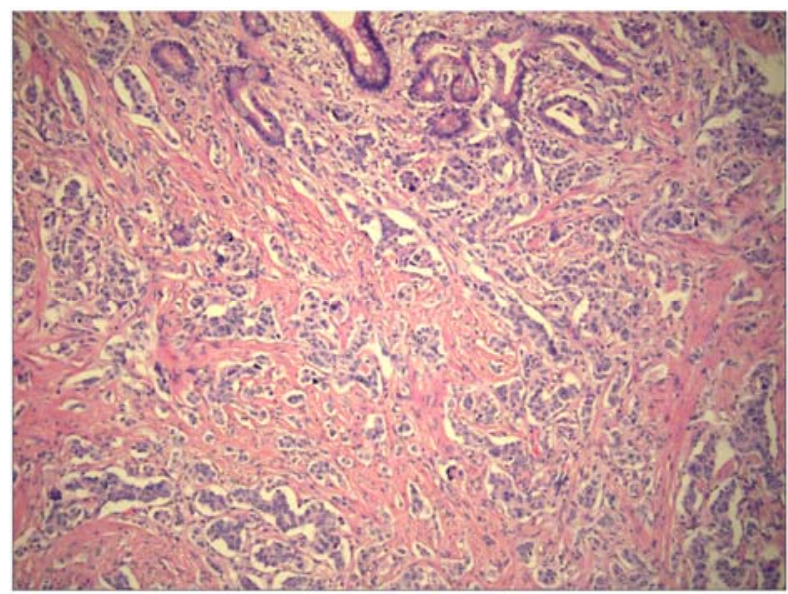

\subsection{Case 2}

A 68-year-old woman presented with microcytic anaemia. She had previously undergone parathyroidectomy. An OGD revealed multiple gastric polyps. Biopsies of five of the polyps revealed features of chronic atrophic gastritis and lowgrade neuro-endocrine tumours. A CT scan showed focal thickening of the greater curve of the stomach with enlarged lymph nodes. She underwent repeat OGD and biopsies demonstrated multiple neuro-endocrine tumours with one showing areas where the neuro-endocrine tumour was admixed with what appeared to be benign glandular foci, indicating a composite epithelial and neuro-endocrine tumour. With these findings and her past medical history, she was screened for multiple endocrine neoplasia type 1 and that diagnosis was confirmed. She underwent further OGD and an EMR, which confirmed the presence of chronic atrophic gastritis and a neuro-endocrine tumour with a tubulo-villous adenomatous element but no features of malignancy.

CT scan, performed three months later, suggested progression of disease and the patient proceeded to a total gastrectomy (see Figure 4). The fundus showed multiple small $(<10 \mathrm{~mm})$ nodules and two larger nodules. Microscopic assessment confirmed the presence of CAG and multiple small and larger neuro-endocrine tumours (see Figure 5). The largest tumour was shown to be a poorly differentiated adenocarcinoma with mixed epithelial and neuro-endocrine differentiation, extensive local and lymphovascular spread and widespread local lymph node involvement (pT4a, pN2) (see Figure 6). No evidence of a neuro-endocrine tumour of gastrinoma type was demonstrated in the stomach or duodenum of the resection specimen. 
Figure 4. The gastrectomy of Case 2. Once again, the oesophageal aspect is central and above. The fundus and stomach are festooned with multiple small polypoid lesions. Two appear larger and represented mixed epithelial and neuro-endocrine tumours, MANECs, with adenocarcinoma.

Figure 5. Case 2. This shows the features of chronic atrophic gastritis with extensive intestinal metaplasia of the mucosa with an underlying neuro-endocrine tumour.

Figure 6. Case 2. High power of one area of the largest tumour. There are neuro-endocrine elements but there is also glandular differentiation, here relatively well differentiated. Elsewhere there was poorly differentiated adenocarcinoma.
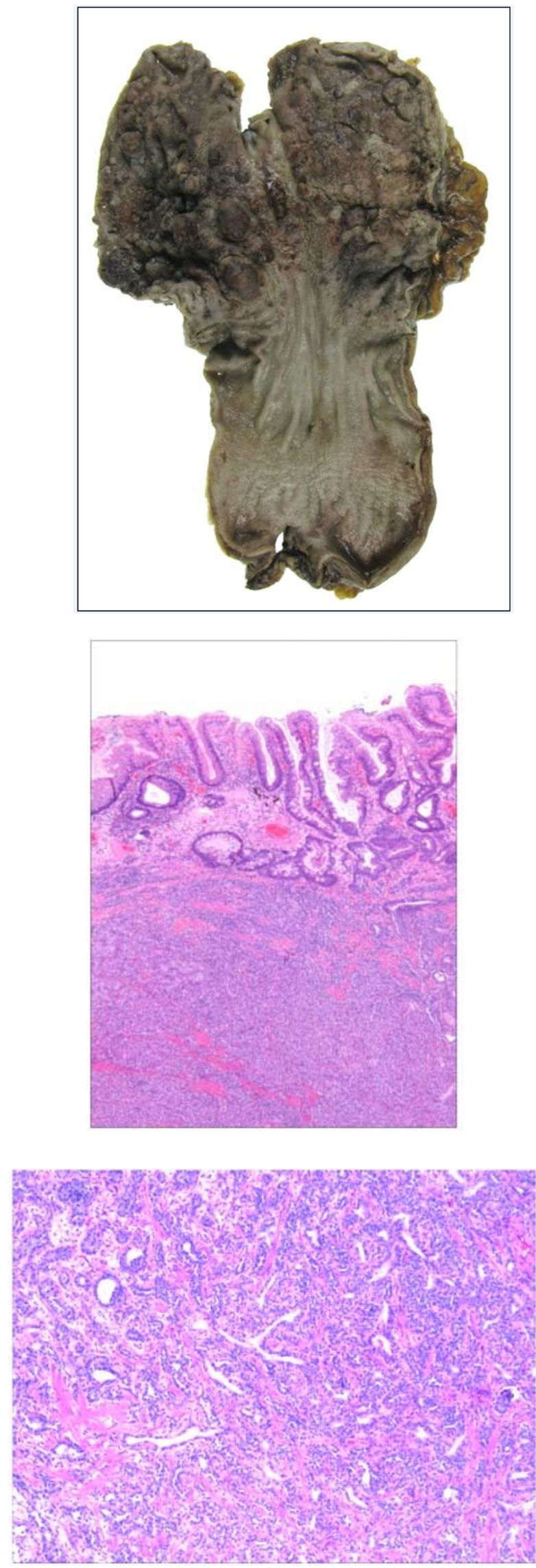

ISSN 2331-2726 E-ISSN 2331-2734 


\section{Discussion}

These two cases highlight some of the difficulties with the management of neuro-endocrine tumours of the stomach. In Western populations, the majority of these tumours arise on the basis of chronic atrophic gastritis and are multiple, small and indolent: they are treated conservatively either by surveillance or EMR excision. Indeed, in the biopsy material, that was the appropriate diagnosis in each of these cases and it would have been easy to assume that all the lesions were low grade endocrine tumours and manage the patients conservatively.

In the first case, it was the CT findings which demanded a more aggressive management strategy whilst, in the second case, there was the most unusual co-existence of chronic atrophic gastritis and Zollinger-Ellison syndrome, the latter as part of MEN 1 syndrome, providing two pre-disposing factors for the development of neuro-endocrine tumours of the stomach. In both cases, there were innumerable polypoid lesions of the stomach such that endoscopic biopsy of all of them was not practical. However, the two gastrectomy specimens revealed both MANEC tumours and pure adenocarcinoma, both of which are also recognised complications of chronic atrophic gastritis.

Whilst it is important to understand that most smaller neuro-endocrine tumours of the stomach are indolent and should be managed conservatively, the two diseases that predispose to gastric neuro-endocrine tumours, chronic atrophic gastritis and Zollinger-Ellison syndrome, one common and one distinctly rare, also predispose to more aggressive tumours, both MANECS and pure gastric-type adenocarcinomas. It may not be practical to sample all the lesions endoscopically for histological assessment and thus, in multi-disciplinary team assessment, other investigations, particularly radiological imaging, assume greater importance to determine whether one, or more, of the lesions might have a more aggressive phenotype. This underpins the importance of such multi-disciplinary team assessment in all cases of neuro-endocrine tumours of the gastro-intestinal tract.

\section{Acknowledgements}

Both authors have contributed equally to this article.

\section{References}

[1] Modlin IM, Lye KD, Kidd M. A 5-decade analysis of 13,715 carcinoid tumors. Cancer. 2003; 97: 934-959. PMid: 12569593. http://dx.doi.org/10.1002/cncr.11105

[2] Klöppel G, Rindi G, Anlauf M, et al. Site-specific biology and pathology of gastroenteropancreatic neuroendocrine tumors. Virchows Arch. 2007; 451; S9-S27. PMid: 17684761. http://dx.doi.org/10.1007/s00428-007-0461-0

[3] Klöppel G. Classification and pathology of gastroenteropancreatic neuroendocrine neoplasms. Endocrine-related Cancer. 2011; 18: S1-S16. PMid: 22005112. http://dx.doi.org/10.1530/ERC-11-0013

[4] Panzuto F, Nasoni S, Falconi M, et al. Prognostic factors and survival in endocrine tumor patients: comparison between gastrointestinal and pancreatic localization. Endocr Relat Cancer. 2005; 12: 1083-1092. PMid: 16322345. http://dx.doi.org/10.1677/erc.1.01017

[5] Rindi G, de Herder WW, O'Toole D, et al. Consensus guidelines for the management of patients with digestive neuroendocrine tumors: the second event and some final considerations. Neuroendocrinology. 2008; 87: 5-7. PMid: 17940331. http://dx.doi.org/10.1159/000109975

[6] Ramage JK, Davies AH, Ardill J, et al. Guidelines for the management of gastroenteropancreatic neuroendocrine (including carcinoid) tumours. Gut. 2005; 54(suppl 4); 1-16. PMid: 15888809. http://dx.doi.org/10.1136/gut.2004.053314

[7] Rindi G, Luinetti O, Cornaggia M, et al. Three subtypes of gastric argyrophil carcinoid and the gastric neuroendocrine carcinoma: a clinicopathologic study. Gastroenterology. 1993; 104: 994-1006. PMid: 7681798.

[8] Scherubl H, Cadiot G, Jensen RT, et al. Neuroendocrine tumors of the stomach (gastric carcinoids) are on the rise: small tumors, small problems? Endoscopy. 2010; 42: 1-8. PMid: 20669078. http://dx.doi.org/10.1055/s-0030-1255564

[9] Rindi G, de Herder WW, O'Toole D, et al. Consensus guidelines on the management of patients with digestive neuroendocrine tumors: why such guidelines and how we went about it. Neuroendocrinology. 2006; 84: 155-157. PMid: 17312374. http://dx.doi.org/10.1159/000098006 
[10] Oberg K, Astrup L, Eriksson B, et al. Guidelines for the management of gastroenteropancreatic neuroendocrine tumours (including bronchopulmonary and thymic neoplasms). Part II-specific NE tumour types. Acta Oncol. 2004; 43: 626-636. PMid: 15545183. http://dx.doi.org/10.1080/02841860410018584

[11] Abraham SC, Carney JA, Ooi A, et al. Achlorhydria, parietal cell hyperplasia, and multiple gastric carcinoids: a new disorder. Am J Surg Pathol. 2005; 29: 969-75. PMid: 15958864. http://dx.doi.org/10.1097/01.pas.0000163363.86099.9f

[12] La Rosa S, Marando A, Sessa F, et al. Mixed adenoneuroendocrine carcinomas (MANECs) of the gastrointestinal tract: an update. Cancers. 2012; 4: 11-30. PMid: 24213223. http://dx.doi.org/10.3390/cancers4010011

[13] Reu S, Neumann J, Kirchner T. Gastrointestinal mixed adenoneuroendocrine carcinomas. An attempt at classification of mixed cancers. Pathologe. 2012; 33: 31-8. PMid: 22293787. http://dx.doi.org/10.1007/s00292-011-1552-x

[14] Whiting JL, Sigurdsson A, Rowlands DC, et al. The long term results of endoscopic surveillance of premalignant gastric lesions. Gut. 2002; 50: 378-81. PMid: 11839718. http://dx.doi.org/10.1136/gut.50.3.378

[15] Correa P. Human gastric carcinogenesis: a multistep and multifactorial process - First American Cancer Society Award Lecture on cancer epidemiology and prevention. Cancer Res. 1992; 52: 6735-40. PMid: 1458460.

[16] Ohata H, Kitauchi S, Yoshimura N, et al. Progression of chronic atrophic gastritis associated with Helicobacter pylori infection increases risk of gastric cancer. Int J Cancer. 2004; 109: 138-43. PMid: 14735480. http://dx.doi.org/10.1002/ijc.11680 